\title{
Specific horticulture therapy guidelines in the landscaping of Cluj-Napoca hospital facilities - improving mental and behavioural healthcare
}

\author{
Timea HITTER, Maria CANTOR, ${ }^{1}$ Erzsebet BUTA \\ ${ }^{1}$ Department of Horticulture and Landscaping, Faculty of Horticulture, \\ University of Agricultural Science and Veterinary Medicine, Cluj-Napoca \\ e-mail:marcantor@yahoo.com
}

\begin{abstract}
In the beginning, nature was an irreplaceable environment for humans. The concept of horticulture therapy (HT) denotes the use of ornamental plants to improve people's health based on the connection between landscape architecture principles, design elements, and guidelines in healthcare facility gardens. In HT, people can improve and maintain health; so, gardens must provide only beneficial effects for users (patient, family, staff), testing design elements, which can be a scroll direction in garden, point of interest, connection with nature. This paper presents a case study analysis of the current landscape architecture standpoint: one of the Cluj-Napoca clinics, where HT can improve patients' well-being.
\end{abstract}

Keywords: design elements, therapeutic landscape, plants

\section{Introduction}

Horticulture therapy was mentioned in ancient Egypt, but the history of healing gardens goes back many centuries, as at one time nature was seen as intrinsic to healing - still, this important connection had been largely lost by the twentieth century [1]. In 1806, hospital staff in Spain began emphasizing the use of agricultural and horticultural activities in their programming for patients with mental disabilities. The favourable evidence encouraged other institutions to realize the benefits of working with the soil for people with mental disabilities [2].

The main concept of horticulture therapy of using nature (especially ornamental plants) in order to improve human health has been gaining ground since the $70 \mathrm{~s}$ and $80 \mathrm{~s}[1]$. 
Based on this statement mentioned before, the main topic of this research is to study the connection between landscape architecture principles and design elements used as guidelines in healthcare facility gardens.

In order to provide a natural environment, horticulture therapy is an activity through which people can maintain and improve the health of their body, mind, and soul. The five senses of the human body (sight, smell, taste, touch, and hearing) are used to interact with plants by colour, flavour, and aroma and texture [3].

It was confirmed that when people come in contact with plants through a variety of gardening activities, such as planting and caring for plants, besides the aesthetic function, it generates feelings of comfort and improves the quality of life [3].

History and research made so far in the field of horticulture therapy show that contact with nature has beneficial effects on humans. From the theoretical point of view, using plants in constructed landscape significantly improves the patient's recovery period from any medical problems.

For example, the mental health benefits of interaction with landscape are actively and/or passively numerous and well-established. For this purpose, healthcare institutions in Europe and the United States of America make healing green spaces used for horticulture therapy such as: a garden at a crisis shelter for women and children survivors of domestic violence (Danner's Garden, Copenhagen, Denmark), Alnarp Rehabilitation Garden (Alnarp, Sweden), Rosecrance healing garden (Griffin Williamson adolescent treatment centre, Rockford, Illinois) [1].

In Romania, at the Mocrea Psychiatric Hospital in Arad, there was established the first therapeutic garden in 2014 for a Romanian healthcare facility, having an area of 1,500 square meters, where there are over 3,000 flowers and shrubs planted on site. In this green space, more than 40 hospitalized patients have the opportunity to be involved in horticulture therapy activities [4].

At this moment in Romania, horticulture therapy principles are insufficiently studied and applied in healthcare facilities, but the requirements for it are significant. The current Romanian laws have sufficient requirements for green space areas close to hospitals (10-15 square meters/patient), according to Decision No 525 of 27 June 1996 for approval of General Regulation - Urban Planning [5], but in many cases these are not complied with in practice. The benefits of interacting with nature for people with mental disorders have been various, welldocumented, and historically certified from the beginning of the horticultural discovery. These conditions affect most people either directly or indirectly. One of four people is experiencing mental disorders, which in the most cases are not detected or judiciously treated. These conditions can affect people of all ages who are emotionally affected, including depression, attention deficit disorder (ADD), autism, suicide, bulimia, or addiction to narcotic substances. 
The purpose of this study was to analyse the current landscape architecture standpoint in Cluj-Napoca - Child and Adolescent Psychiatry and Addiction Clinic, where, by using horticulture therapy principles, patients' wellbeing can be improved.

\section{Materials and methods}

In May 2016, the green area of Child and Adolescent Psychiatry and Addiction Clinic of Cluj-Napoca was the place for a therapeutic landscaping intervention. This clinic is located on Ospătăriei Street, in Plopilor neighbourhood, which covers an area of approximately 2,000 square meters. At this moment, the studied hospital is one of three paediatric psychiatric clinics in Romania which offer cure and medication for 25 patients, children and teenagers as well, and is the workplace for a teaching clinic for university and postgraduate programmes.

In the spring of 2016, at the initiative of School for Public Health BabeşBolyai University and a group of $3^{\text {rd }}$-year students taking part in this programme, a multidisciplinary team (researchers, doctors, psychologists, landscape architects, architects, and students) was formed to develop and implement the green area of the clinic mentioned before.

During the second semester of the academic year 2015-2016, students had to attend the course of project development for mental health. They studied alternative treatment of mental disorders, the use of horticulture therapy in the perspective of healing gardens. The practical part of the project consisted in the development of some main stages of the therapeutic garden elements.

The new landscape plan for the hospital green space aimed at having only beneficial effects on users (patient, family, and staff). Using the landscape architecture design elements, such as line, shape, colour, value, and texture in the green space of healthcare facility, this can provide for patients and also visitors a scroll direction of the garden (line and shape), a point of interest (colour and value), and a connection with the nature or character of the plants (texture) in the garden. The hospital's green space must have only beneficial effects on people.

At the start of the landscaping project proposal of the clinic's green space, the site was analysed according to the elements of the therapy through landscape: horticulture therapy and sensory arrangement - Fig. 1 . 


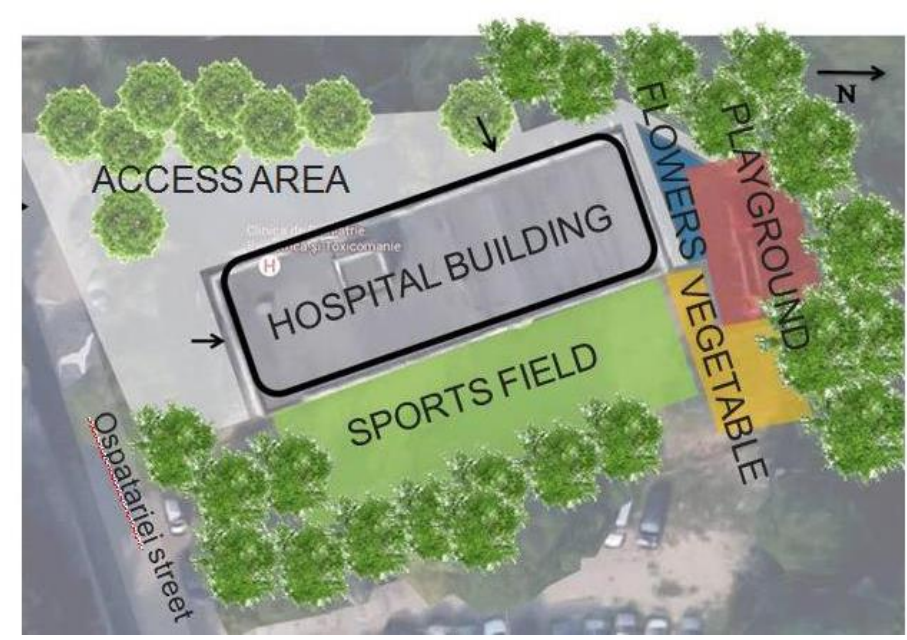

Figure 1. Land distribution of the landscaping plan - Child and Adolescent Psychiatry and Addiction Clinic of Cluj-Napoca

\section{Results and discussions}

To achieve the effect of horticulture therapy according to planning principles, it was absolutely necessary to make an analysis on how the landscaping projects need to be developed for this type of institution and also how they can be integrated for each type of illness that requires a specific design guideline in the garden.

According to Decision No 525 of 27 June 1996 for approval of General Regulation - Urban Planning [5], the green space area respects the required 10-15 square meters/patient, a ratio accomplished for the number of hospitalized people. A local case study analysed all project data such as location, addressability, profile, architectural programme, green space specifics, and user needs and requirements.

Being a sanitary facility with a paediatric profile, where diseases such as mental or chromatic disorders are treated, the purpose is to use blue or white shades of colour that have relaxing effects. In order to realize a surprise element and occupy the centre of attention, the use of ornamental plants with complementary colour inflorescences was proposed - they would use yellow (Fig. 2).

The ornamental plants proposed for the planting design are as follows: for its calming properties, Lavandula augustifolia, Tropaeolum majus for being an edible plant [6], installed together with groups of wild lily (Hemerocallis sp.). Due to their decorative colours, they mostly used perennial species to obtain a spring flower design - therefore, bulbous plantings are made each autumn (Tulipa sp.) [7]. Analysing the decorative plant species through the leaves, the plants already 
existing on the site (Sedum sp.) are proposed for reuse because of the specific texture and low-maintenance species in terms of green area sustenance [8].

A random, marginally flattened Stachys group can be positioned for the velvety foliage besides the autumn lily (Hosta sp.) [9]. From the group of ornamental grasses, the most suitable species is Miscanthus sinensis because, due to the shape of the leaf and the pendent port, it gives a feeling of comfort to the touch and, on the action of climatic factors such as the wind, presents an aesthetically unusual figure [10].

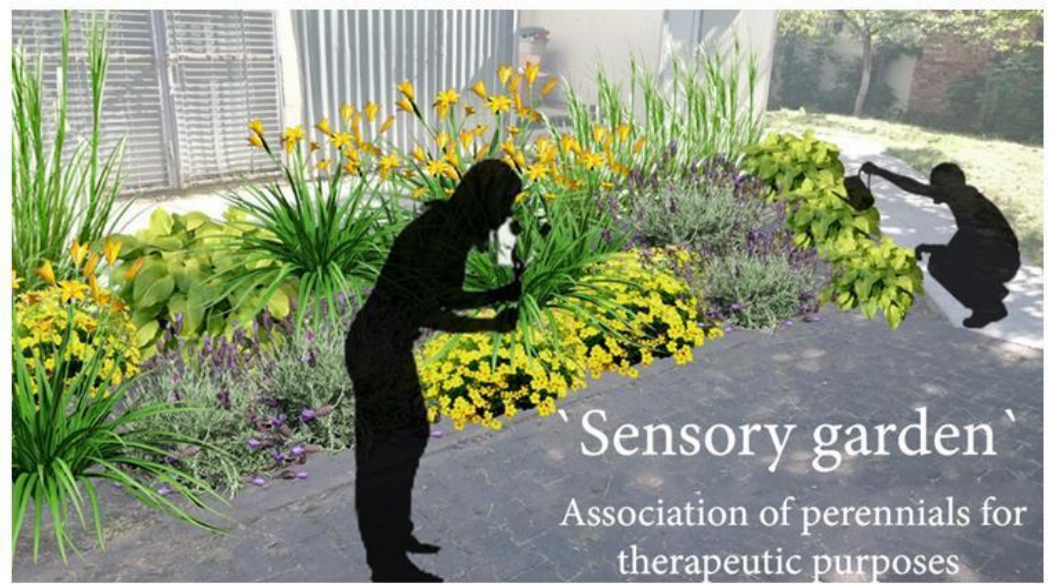

Figure 2. The sensory garden with perennial floral plants - Child and Adolescent Psychiatry and Addiction Clinic of Cluj-Napoca

Near this planting group, as part of the "sensory alley", rocks or gravels of different sizes and natural elements, such as bark, cones, or straw, were proposed.

The lack of sufficient seating generated the idea of using recycled briquettes and spread them through the garden (Fig. 3). And this way children would become curious to venture through the garden and would spot the centre of interest only to stay for a while.

In order to have some privacy and a place to stay, even if not arranged, it was proposed to use recycled wood pallets for the arrangement of this area.

For a more comfortable stay, people can enjoy the sitting spot. The corner already offers its own privacy due to its configuration, but with the help of vertical gardens in wood pallets presented in Fig. 4 the place can be arranged more naturally. This way, ill children will be getting closer to nature. Clinical treatment also needs special psychotherapy features, the use of a vertical garden set-up, the application of HT principle, and to create a conducive environment to implement these activities. 


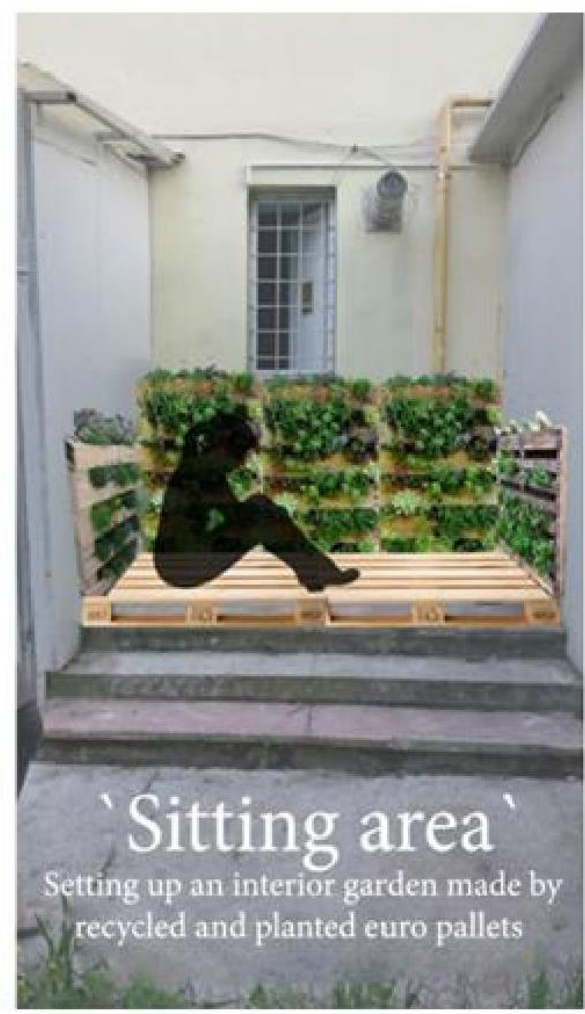

Figure 3. Sitting area - Child and Adolescent Psychiatry and Addiction Clinicof Cluj-Napoca

Regarding the gardening area, raised beds, as shown in Fig. 4, can be planted with vegetable species such as tomatoes (Solanum esculentum), pepper (Capsicum annuиm), parsley (Petroselinum crispum), and spinach (Spinacia oleracea) for the edible part of the garden [11]. Culinary herbs and edible species, such as Mentha spicata, Thymus vulgaris, and Basilicum, always provide a fresh flavour for a simple walk through the garden [12].

In the first phase of the project, the land was cleaned, arranged, and planted with vegetables, while the children were curious, interested, and eager to be involved in the planting or sowing stage. Similar results using horticulture therapy were reported by Marcus Cooper [1] all over the analysed healthcare green spaces addressing the mental health issue. 


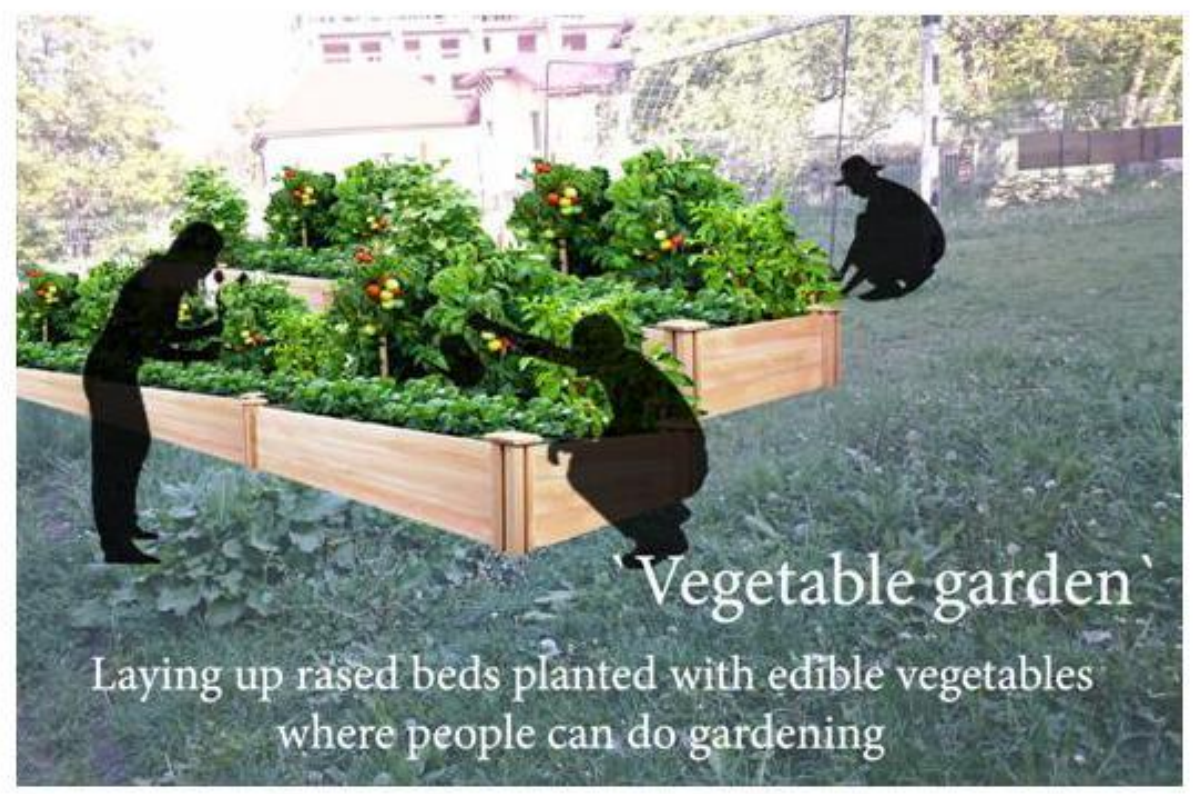

Figure 4. Raised beds for the vegetable garden - Child and Adolescent Psychiatry and Addiction Clinic of Cluj-Napoca

\section{Conclusion}

The sensory design aims for the Child and Adolescent Psychiatry and Addiction Clinic of Cluj-Napoca was to use natural, living, and inert materials. According to the aesthetic and therapeutic features, the landscaping project proposed decorative plants through leaves and flowers. For the planting design, it was set in the proximity of the access points, near the playground and the perennial plants composition. In this way, the green area will offer sustainable solutions for all user requirements, thus fulfilling its final aim: long-term physical and mental improvement. In conclusion, it is hoped that the green space will be exploited to the maximum of its therapeutic capacity in order to improve patients' health in a natural way.

\section{Acknowledgements}

This paper could be published with the support and collaboration of an interdisciplinary team formed by students and teachers from School for Public Health, Babeş-Bolyai University of Cluj-Napoca and hospital coordinators of Child and Adolescent Psychiatry and Addiction Clinic of Cluj-Napoca. 


\section{References}

[1] Cooper Marcus, C., Sachs, A. N. (2014), Therapeutic landscape - an evidence-based approach to designing healing gardens and restorative outdoor spaces. Wiley, New Jersey.

[2] Simson, P. S., Straus, H. C. (1998), Horticulture as therapy: principles and practice. Binghamton, New York: Haworth Press.

[3] Iliescu, A. F. (2003), Arhitectură peisageră. Bucharest: Ceres.

[4] http://romanialibera.ro/societate/sanatate/ce-le-ofera-pacientilor-prima-gradina-terapeutica-dinromania-338707.

[5] Decision No. 525 of 27 June 1996 for approval of General Regulation - Urban Planning, Romania.

[6] Drăghia, L., Chelariu, L. (2011), Floricultură. Ion Ionescu de la Brad, Iași.

[7] Cantor, M., Buta, E. (2009), Floricultură - Indrumător de lucrări practice. Cluj-Napoca: Todesco.

[8] Băla, M. (2012), Floricultură generală și specială. Timișoara: Partos.

[9] Cantor, M. (2009), Floricultură generală. Cluj-Napoca: Todesco.

[10] Toma, F. (2009), Floricultură și artă florală, vol. 4: Specii utilizate pentru decorul parcurilor și grădinilor. Bucharest: INVELMultimedia.

[11] Sima, R. (2009), Legumicultură - Sursă de hrană și potențial ornamental. Cluj-Napoca: AcademicPres.

[12] Șelaru, E. (2007), Cultura florilor de grădină. Bucharest: Ceres. 